\title{
Editorial
}

\section{Ebola Virus Disease and Blood Purification Techniques}

\author{
Claudio Ronco
}

Department of Nephrology, Dialysis and Transplantation, International Renal Research Institute of Vicenza (IRRIV), San Bortolo Hospital, Vicenza, Italy

The relationship between viral infection and extracorporeal therapies goes back to the beginning of hemodialysis history [1]. In the early seventies, blood handling outside the body with little or no preventive measures led to an epidemic of hepatitis B virus contamination among patients and dialysis nurse and physicians. Subsequently, a careful campaign of prevention with the installment of specific measures such as patient separation, hardware disinfection, avoidance of cross contamination due to inappropriate maneuvers, disposable dialyzers and ultimately, vaccination, have significantly reduced the incidence and the prevalence of hepatitis B positivity among dialysis patients [2]. The subsequent phase was the so called non-A non-B epidemic, finally leading to the discovery of hepatitis $\mathrm{C}$ virus infection [3]. Again, particular care and prevention measures have recently reduced the incidence and prevalence of positivity among dialysis patients [4]. Since 1982 when the first case of Acquired Immunological Deficiency Syndrome (AIDS) was identified in New York, there has been a great deal of discussion regarding HIV infection and dialysis and in recent years, the management of HIV patients in chronic dialysis has practically become routine with specific recommendations and measures [5].

Several questions regarding viral infections and hemodialysis have been raised and not all have received a complete answer:

- What is the relation between the virus particle size and membrane pore diameter?

- Is the virus cleared by dialysis membranes?

- Is the viral load high in the effluent dialysate?
- Should dialysate or effluent bags be disposed of in a particular way?

- How should the infected patient be handled and how should he/she be located in the chronic dialysis center?

- Is there any particular care to be used in acute critically ill patients beyond careful handling of potentially contagious body fluids?

- Is there a particular technique to be utilized for blood access, extracorporeal circuit and anticoagulation management?

- How should the dose of antiretroviral drugs be adjusted depending on dialysance?

- How should other medications necessary for treating associated comorbidities be adjusted?

- Should all infected patients be excluded from randomized trials?

Further questions have emerged with the use of continuous renal replacement therapies (CRRT) and derived techniques in patients with critical illness induced by viral infections [6]. Often these patients display signs and symptoms similar to sepsis or septic shock with high cytokine concentrations in blood, endothelial dysfunction and ultimately organ failure. In such patients, CRRT, high-volume hemofiltration, coupled plasma filtrationadsorption and other extracorporeal techniques have been used not only to manage uremic symptoms derived from kidney dysfunction but also to restore homeostasis and improve immunological response [7].

Recent discoveries have led to the development of specific extracorporeal sorbent techniques to reduce viral

\section{KARGER 125}

(c) 2015 S. Karger AG, Base

0253-5068/15/0384-0273\$39.50/0 
particle concentrations in blood. The application of a specific device called 'Hemopurifier' has been advocated to reduce viral load in several acute viral infections [8]. Blood is circulated through a hollow fiber plasma filter that has a specific sorbent matrix stuffed in the compartment external to hollow fibers. Due to the fluid mechanics inside the device, plasma is produced from whole blood in the proximal part of the fibers and it is forced to flow through the sorbent bed. In the distal part of the device, plasma reenters the hollow fibers by a backfiltration mechanism. No plasma loss occurs since plasma never leaves the device (the plasma ports are left capped). According to the company's specifications (Aethlon Medical Inc., San Diego Calif., USA), the sorbent is highly specific for glycoproteins (GP) that viral envelopes. Viral particles are thereby captured and their concentration in blood is significantly reduced [9]. This process, called 'Lectin Affinity Plasmapheresis', is based on the concept of affinity chromatography developed in the 1970s [10]. A unique lectin protein (Galanthus nivalis agglutinin, GNA) from Galanthus nivalis (the common snowdrop) has a high affinity to the mannose-rich GP that ubiquitously populate the surface of enveloped viruses $[11,12]$ to inter alia mediate entry into host cells. This device has been used either alone or in series with a hemodialyzer and has displayed encouraging results both in vitro and in vivo on hepatitis $C$ and HIV infected blood. Assuming a delicate equilibrium between the viral load and the immunological system, the eradication of a viral infection may be realized only by tipping the balance in favor of the innate immune response by lowering the circulating viral particle concentration in blood.

The world is now facing a new challenge. Ebola virus disease (EVD) has affected quite a large number of individuals in West Africa. Ebola virus is transmitted by the direct contact with body fluids and therefore heath care workers caring for patients with EVD are at risk for crosscontamination and infection.

Ebola virus causes a highly lethal hemorrhagic fever in man. EVD infection involves massively disseminated viral replication and host immune dysregulation with uncontrolled cytokine secretion. Signs and symptoms are secondary to a systemic inflammatory response resembling sepsis or septic shock. Endothelial cell damage and coagulation disorders result in a capillary leak and hemorrhagic syndrome, ultimately leading to organ failure and death. The new challenge is represented by the patients with EVD that require medical care and possibly multiple organ support including renal replacement therapy (RRT). Three aspects are currently under dis- cussion in this area: the first aspect relates to the prevention of transmission of disease to healthcare workers. Faubel et al. in this issue extensively discuss the modes of Ebola virus transmission and recommend protocols to protect healthcare workers [13]. Experience now indicates that with appropriate planning and protocols, it is possible to successfully treat EVD patients with advanced supportive care (mechanical ventilation and RRT) while avoiding transmission to healthcare providers. The second aspect deals with the prescription and delivery of optimal supportive therapy in order to maximize patients' benefits while avoiding complications such as hypotension, bleeding organ damage. There is a common agreement that these patients should be treated as critically ill and severely unstable from the hemodynamic point of view. The capillary leak syndrome often observed requires limited rates of ultrafiltration with constant attention to intravascular refilling and effective circulating blood volume. The third aspect describes the potential benefits achievable with extracorporeal therapies in terms of viral load reduction with 'Lectin Affinity Plasmapheresis' or in terms of cytokine removal with high cut-off membranes, high-volume hemofiltration, coupled plasma filtration-adsorption and other CRRT techniques. In this issue, the paper of Büttner et al. well describes a case of EVD in a patient infected in Africa and subsequently moved to Germany for immediate supportive care. The combination of pharmacological support, critical care management and the application of extracorporeal 'Lectin Affinity Plasmapheresis' seems to have played a major role in the final positive outcome of the patient [14].

It seems as though we are getting ready to face the different problems of EVD in patients who require renal replacement therapy and in some cases even beyond this, proposing new treatments to limit the impact of viral load, especially in the early phases of the contamination. The challenge, however, remains open.

\footnotetext{
References $>1$ Friedman EA, Thomson GE: Hepatitis complicating chronic haemodialysis. Lancet 1966; 2:675-678.

2 Maupas P, Goudeau A, Coursaget P, Drucker J, Bagros P: Immunisation against hepatitis B in man. Lancet 1976;1:1367-1370.

-3 Deane N, Chalmers TC: Hepatitis and hemodialysis revisited. JAMA 1981;245:171-172.

4 Jadoul M, Barril G: Hepatitis C in hemodialysis: epidemiology and prevention of hepatitis C virus transmission. Contrib Nephrol 2012; 176:35-41.
} 
5 Geddes C, Lindley E, Duncan N: Renal Association Clinical Practice Guideline on prevention of blood borne virus infection in the renal unit. Nephron Clin Pract 2011;118(suppl 1):c165-c188.

-6 Bentley ML, Hollistera AS, Hansenb AC Smith JA, Cain JS: Peramivir pharmacokinetics in a patient receiving continuous veno-venous hemodiafiltration during the 2009 H1N1 influenza A pandemic. Int J Clin Pharmacol Ther 2014;52:1105-1111.

7 Ronco C, Tetta C, Mariano F, Wratten ML, Bonello M, Bordoni V, Cardona X, Inguaggiato P, Pilotto L, d'Intini V, Bellomo R: Interpreting the mechanisms of continuous renal replacement therapy in sepsis: the peak concentration hypothesis. Artif Organs 2003;27: 792-801.

-8 Tullis RH, Duffin RP, Handley HH, Sodhi P, Menon J, Joyce JA, Kher V: Reduction of hepatitis $C$ virus using lectin affinity plasmapheresis in dialysis patients. Blood Purif 2009;27: 64-69.
\9 Escudero-Pérez B, Volchkova VA, Dolnik O, Lawrence P, Volchkov VE: Shed GP of Ebola virus triggers immune activation and increased vascular permeability. PLoS Pathog 2014;10:e100459.

10 Lamontagne F, Clément C, Fletcher T, Jacob ST, Fischer WA 2nd, Fowler RA: Doing today's work superbly well - treating Ebola with current tools. N Engl J Med 2014;371:15651566.

11 Kreuels B, Wichmann D, Emmerich P, Schmidt-Chanasit J, de Heer G, Kluge S, Sow A, Renné T, Günther S, Lohse AW, Addo MM, Schmiedel S: A case of severe Ebola virus infection complicated by gram-negative septicemia. N Engl J Med 2014;371:2394-2401.
2 Bah EI, Lamah MC, Fletcher T, Jacob ST, Brett-Major DM, Sall AA, Shindo N, Fischer WA 2nd, Lamontagne F, Saliou SM, Bausch DG, Moumié B, Jagatic T, Sprecher A, Lawler JV, Mayet T, Jacquerioz FA, Méndez Baggi MF, Vallenas C, Clement C, Mardel S, Faye $\mathrm{O}$, Faye O, Soropogui B, Magassouba N, Koivogui L, Pinto R, Fowler RA: Clinical presentation of patients with Ebola virus disease in Conakry, Guinea. N Engl J Med 2015;372: 40-47.

13 Faubel S, Franch H, Vijayan A, Barron MA, Heung M, Liu KD, Koyner JL, Connor MJ Jr: Preparing for renal replacement therapy in patients with Ebola virus disease. Blood Purif 2014;38:276-285.

14 Büttner S, Koch B, Dolnik O, eickmann M, Freiwald T, Rudolf S, Engel J, Becker S, Ronco $\mathrm{C}$, Geiger H: Extracorporeal virus elimination for the treatment of severe Ebola virus disease - first experience with lectin affinity plasmapheresis. Blood Purif 2014;38:286-291. 